\title{
Translating Interfaces in the Ms. Magazine Archive
}

Fabiola Hanna and Irene Lusztig

DOI:10.15664/fcj.v19i0.2386

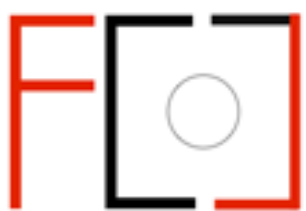

Frames Cinema Journal

ISSN 2053-8812

Issue 19 (March 2022)

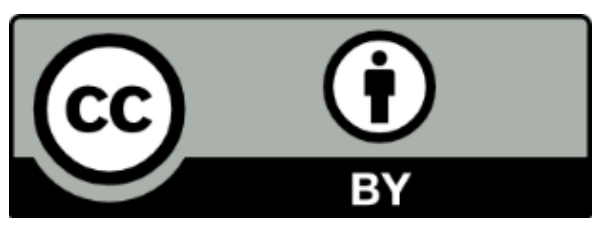


Frames Cinema Journal, Issue 19 (March 2022)

\section{Translating Interfaces in the Ms. Magazine Archive}

Fabiola Hanna and Irene Lusztig

In 1973, an angry woman reports that her boss will not allow her to wear a pantsuit to work. In 1975, a young woman writes about the difficult experience of having a hysterectomy and another tells a painful story of leaving her own children to pursue a new life of feminist self-fulfilment. In 1976, a sixteen-year-old girl haltingly comes out as a lesbian. These are just a few of the thousands of fascinating letters to the editor - far too many to publish - that were mailed to the editorial office of Ms., the first mainstream feminist magazine in the United States. These letters were written by women, men, and children of all ages, from all over the country and from across the spectrum of sexual orientation, religious, racial, and ethnic background, physical ability, and political viewpoint. Spanning deeply personal accounts of individual problems, revelations, and political struggles, the letters describe moving narratives of divorce, abortion, rape, and discrimination (alongside lighter but equally heartfelt debates on topics like masturbation and what to do about female body hair). Now archived in the Schlesinger Library on the History of Women in America at the Radcliffe Institute, these unpublished letters collectively form a kind of encyclopaedia of both the 1970s and the women's movement - an almost literal invocation of the second-wave feminist slogan "the personal is political."

Yours in Sisterhood $(\mathrm{YiS})$ is an iterative, multimodal media project that includes a 2018 feature length performative documentary, produced and directed by filmmaker Irene Lusztig, and a digital archive co-created by Lusztig and digital media scholar-artist Fabiola Hanna that is currently in production. Inspired by the breadth and complexity of the collective portrait of the Women's 
Liberation Movement contained in the Ms. archive of letters, Yours in Sisterhood explores issues of gender politics, social class, race, geography, and public discourse. The project brings a presentday public into dialogue with these historic documents by inviting a wide range of project participants to perform and respond to letters drawn from the archive. While the digital YiS archive is still a work in progress, we put forward our work on this large-scale interactive project as a case study for considering methodologies and practices of archival translation as we move from original paper documents in an interface of folders and boxes to video footage to a browser-based digital archive. These multiple YiS translations provide a compelling case study because of their significant shifts in interpretation: from the librarian's interface work of cataloguing, preserving, and organising the letters in folders and boxes, to the filmmaker's interface work of editing the video readings into the form of a documentary, and finally to the current collaborative interface work of designing the video database and its query system that populates the online project. Such critical and scholarly attention to the translation of archives at the interface level will facilitate analysis and assessment of the labour, the decisions, and losses and gains of these types of translations.

\section{Translation 0: From boxes of letters at $M s$. Magazine to library archive at Schlesinger}

Throughout the 1970s, the editors of Ms. Magazine read thousands of letters received from readers all over the world, annotated them, organised them, and in some cases edited them when they were selected for publication. Sometimes, they marked the letters with categories, questions, and notes to one another, including occasional inside jokes about the letter-writers. While the magazine only had room to publish twenty or so letters each month - a tiny fraction of the huge volume of correspondence that arrived at the $M s$. editorial office - all were filed at the magazine. It is an unusual practice for a magazine to make unpublished letters to the editor available to the public, 
but $M s$. editors recognised early on that the huge number of letters sent to the magazine collectively constituted an important social history of feminist conversation. In 1981, Ms. made an initial large donation of letters to the Schlesinger Library titled Letters to $M s$., 1972-80, followed by a second even larger donation processed in 2001 (Letters to Ms., 1970-1998, MC 568).

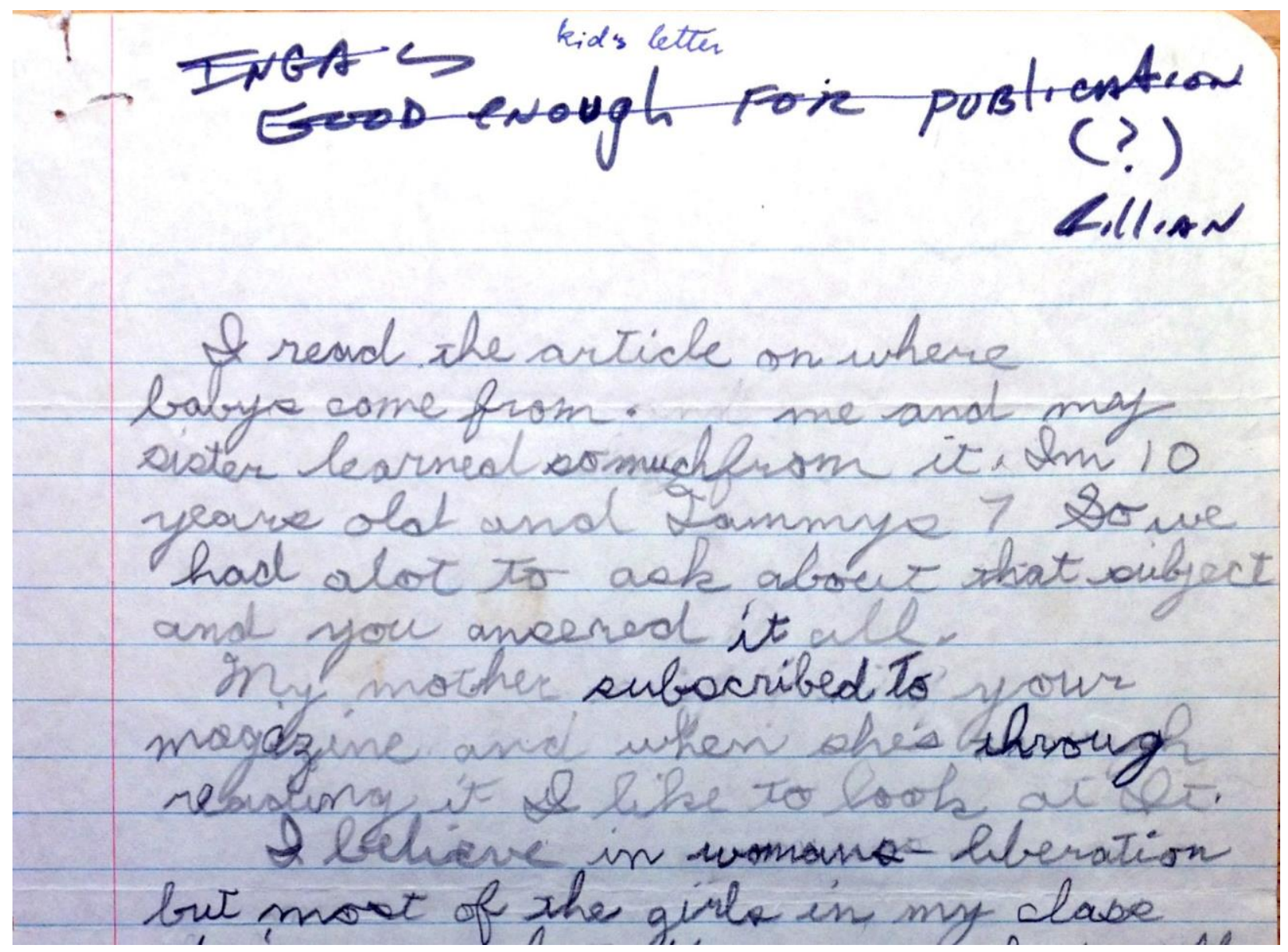

Figure 1. Editor notes on an archival letter in the Letters to $M s$. archive, Schlesinger Library

At the Schlesinger, as with most university special collections, this make-shift archive was processed by the archivists and librarians who were put in charge of this collection. Because the primary mission of the library is to preserve its archives, priority was given to materials that prolong the life of documents for future researchers - such as acid-free boxes and folders - and to the potential for access to this archive based on standard indexing protocols. 


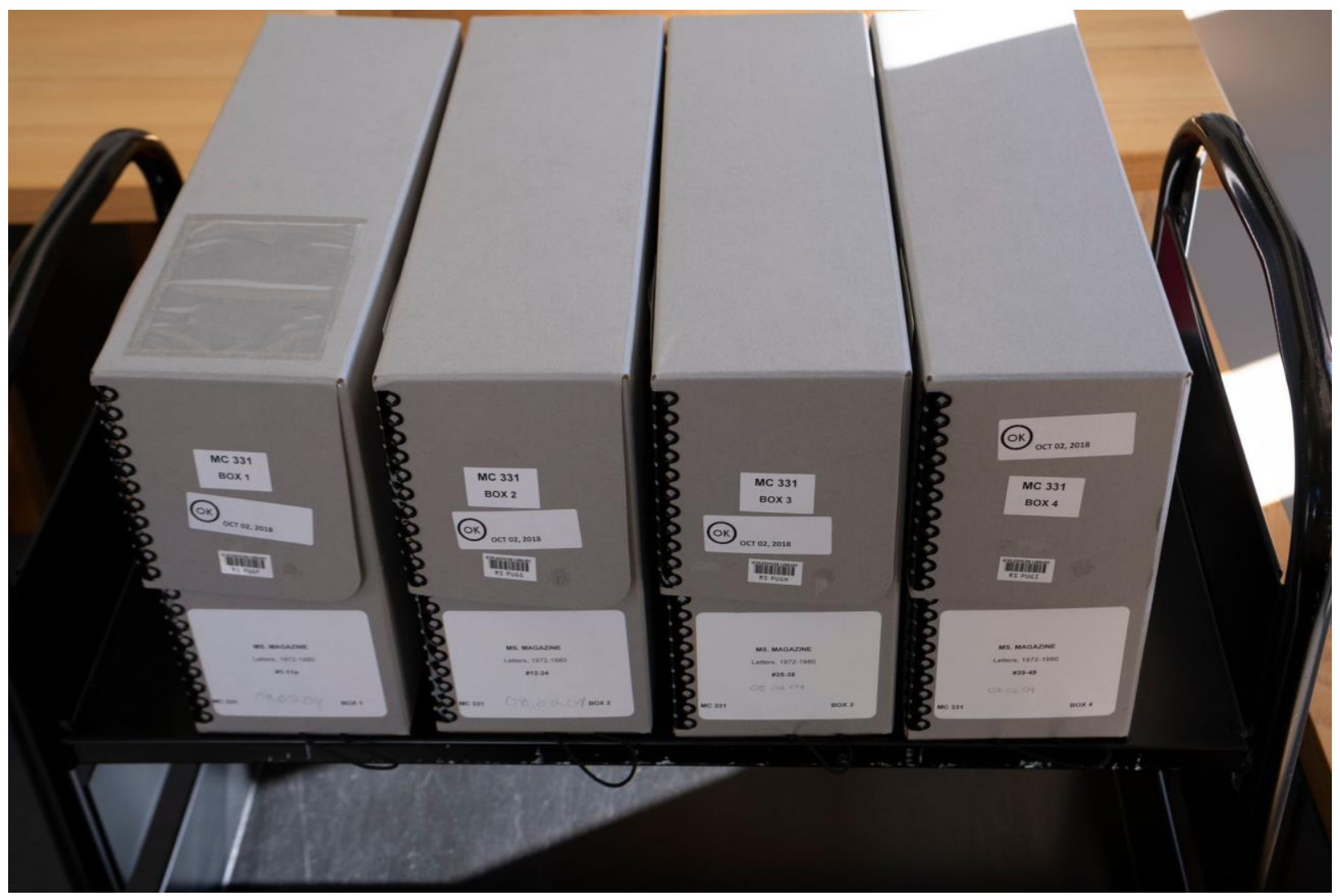

Figure 2. Archival boxes in the Letters to $M s$. archive, Schlesinger Library

Due to limited resources, archivists often face the material necessity of deciding what to discard rather than what to save. In this instance, the online finding aid for the 1972-1980 collection states that "because the files of letters were voluminous and repetitious, they have been weeded to approximately half their original volume. No attempt has been made to preserve a representative sample of letters..." Even though this type of winnowing is common practice in the archival world, the act of culling the collection down to half of the original letters already represents one kind of loss in the move from $M s$. to the Schlesinger. In addition, the archivists at the library implemented a new system to organise the letters by year as well as broad themes such as "kids," "personal," "young women" as seen in the image below. This new classification imposes a way of knowing the content of the archive, a kind of an interpretation manifested in the material 
presentation of the archive. A visitor to the archive is thus invited to engage with the content of the boxes following the interpretation imposed by the archivists at the Schlesinger.

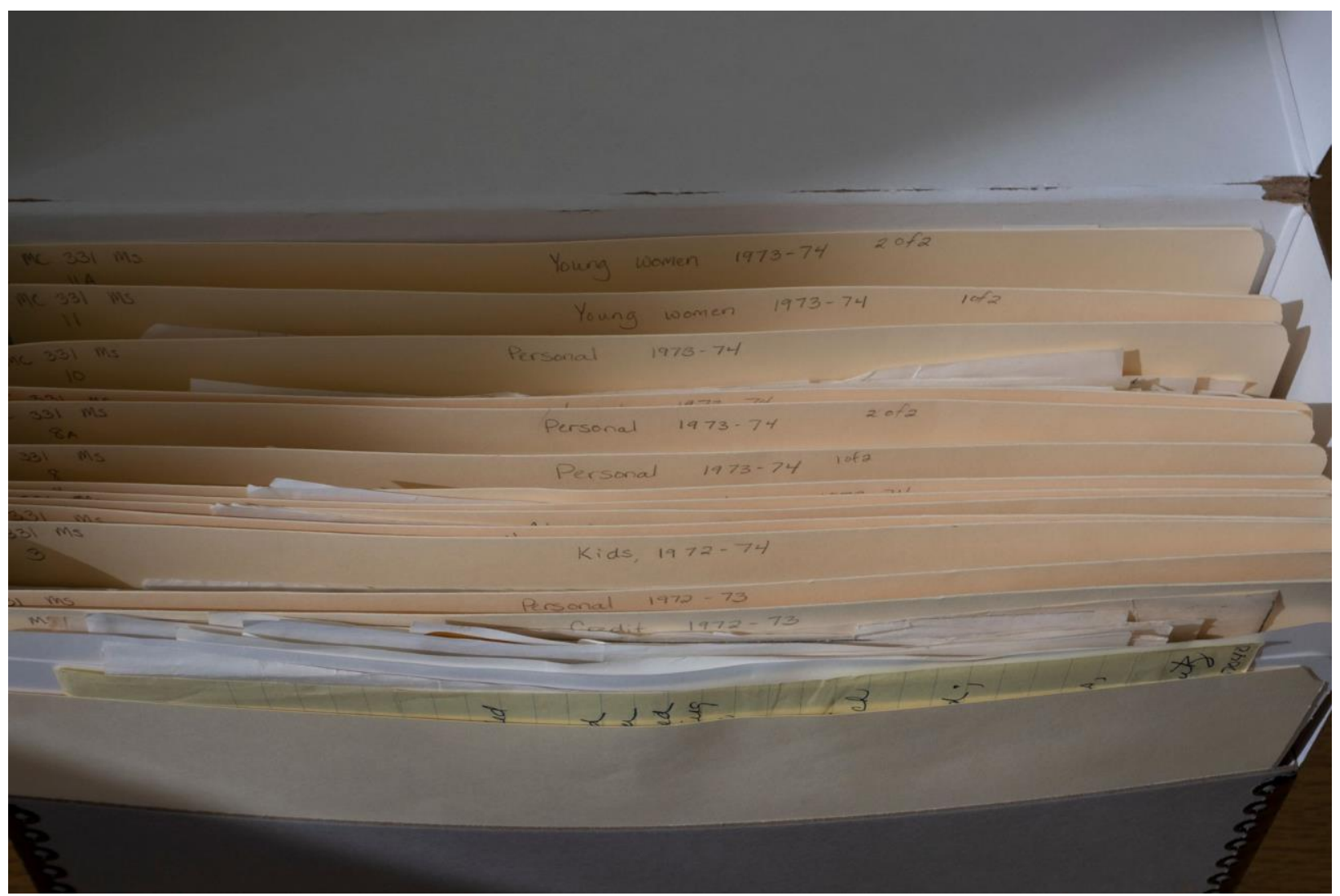

Figure 3. Letters sorted into folders in the Letters to $M s$. archive, Schlesinger Library

\section{Translation 1: From boxes of letters at Schlesinger to film}

This initial translation was followed by a subsequent translation, from written documents organised in a library archive to a feature length film. Over two and a half years between 2015 and 2017, filmmaker Irene Lusztig recruited participants in 32 different US states to read aloud and respond to a selection of letters on camera. This transition to film included several intermediary translations, among them written notes Lusztig made while she read thousands of letters in the archive, and later three digital databases she created. The first digital database consisted of around 
800 letters selected by Lusztig to be considered for inclusion in the film, with background information about the letter writer. The second tracked the geographical locations of these 800 letters on a map of the US and was used to chart possible driving routes through the communities where these letters originated. The final database tracked the film's progress, with information about each filmed letter, including content themes, whether the sound was edited, and technical notes about the filming. These databases are digital intermediaries that were necessary components of the film's workflow but never figure as part of the work. Despite their immaterial presence in the film, these databases imposed yet another translation of the original set of documents.

The film was created through a multi-stage process of reducing and narrowing the archive of letters. The initial process of culling 800 "candidate" letters for filming (out of several thousand read in the archive - a huge volume that would have been unrealistic to film in its entirety given the labour, time, and funding constraints of the project) focused on selecting letters that felt representative or typical of recurring themes and issues, letters that felt exceptional and important - especially around issues of inclusion and representation (this first cut included all letters from self-identified readers of colour, readers with disabilities, and transgender readers) — and letters that fully captured the geographic range contained in the archive, representing every US state and a diverse array of large cities, small towns, and remote rural areas. The materials for the film were produced between 2015 and 2017 across a series of nine road trips through regionally distinct parts of the US (California, the Pacific Northwest, the Southwest, the Southeast, the Midwest, New England, New York, the mid-Atlantic, the Rust Belt, and the Rockies). The shooting methodology developed for the project was simple and formally consistent: each letter was read out loud on camera in the city or town where it was originally written in the 1970s, by a volunteer reader from the same place. 


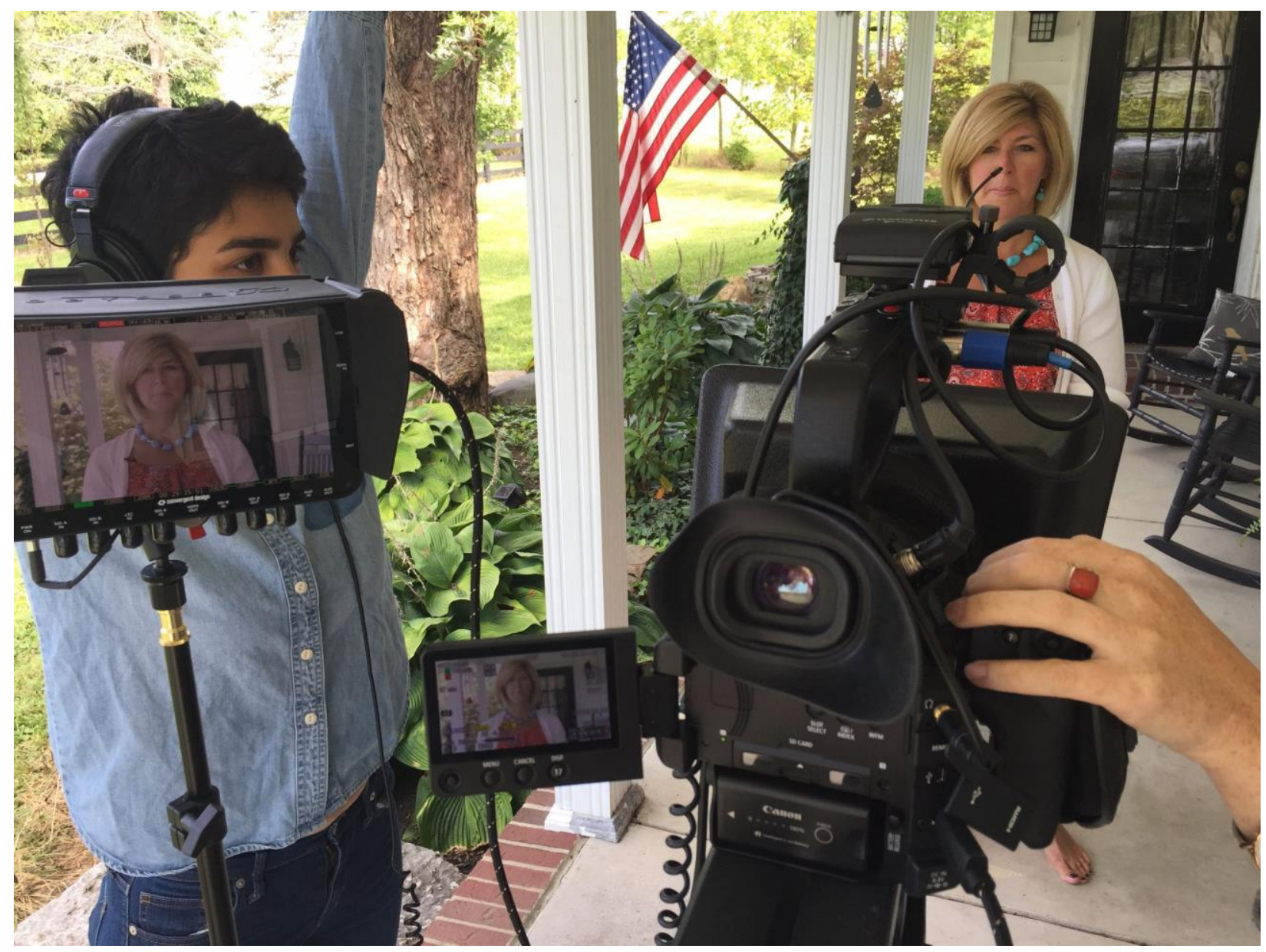

Figure 4. Production still with teleprompter setup.

Each reader was paired with a letter using an idiosyncratic and highly personalised process of "critical casting," wherein readers and letters were carefully matched to encourage generative spaces of dialogue across time (in some cases this meant pairing readers and letters based on common professions, identities, and personal histories, and in other cases pairings were made that, instead, accentuated differences or frictions between contemporary reader and original writer). Readings were filmed outdoors in public space using a portable teleprompter. Filming these unrehearsed readings across multiple takes encouraged a process of real-time listening as readers familiarised themselves with the feeling of embodying someone else's words. And, finally, each reader was invited to respond spontaneously on camera to their reading experience. The finished 
Frames Cinema Journal, Issue 19 (March 2022)

feature film collects 28 of these 306 filmed readings and responses to create a meditation on voice, public discourse, and collective feminist conversation across time. We would like to highlight that together, the decisions taken at each step of the process of making the film, form one particular translation of this archive.

In some ways, the film can be seen as a feminist process of unmaking the published $M s$. letters section - foregrounding and amplifying voices that might otherwise have been marginalised, lost to time, or buried in an archival box. At the same time, the 28 letters presented in the film are a radical distillation of an archive that is abundant, unruly, messy, and expansive. Editing a single channel feature length film with a fixed duration is, by definition, a subtractive process that charts only one possible exploratory path through the archive. The database of 800 "candidate" letters was reduced to 306 filmed letters through a process of elimination based on geography, using the driving route visualisations produced by the project map database: letters that could be mapped in clusters were easier to film whereas "outlier" letters - for example isolated single letters far from others, such as letters sent from Hawaii or Southern Texas - were left out, and based on the availability of volunteer readers in different places. And the pool of 306 filmed readings was even more drastically reduced to the small number of readings that could fit into a standard feature film run time of 101 minutes. For the film iteration of this project, editing decisions were made to represent as many kinds of geographical communities as possible (which meant significantly reducing the presence of letters from places that generated the largest number of letters, like New York City and Los Angeles) and, as well, the selection prioritised questions of race and gender diversity (ultimately perhaps at the expense of other important issues - for example letters about abortion are not included in the film). Ironically, this process of narrowing mirrors the original gatekeeping done by $M s$. editors who decided which letters were publication worthy. As much as 
the published letters section in the magazine reflects the concerns and voices that felt most visible and urgent in the 1970s, the film's curatorial focus might be understood as a snapshot of a postTrump moment where questions of identity, inclusion, and representation have taken centre stage in feminist debates.

While there are many gains to presenting these archival texts in an accessible fixed-duration cinematic form that can be screened in cinemas, museums, classrooms, and streaming platforms (unlike a library building that requires travel and physical presence to access the original texts), we also understand that this tightly curated presentation of archival texts presents certain forms of loss. The materiality of the original archive is absent from the film - viewers do not see visual details of the letters, handwriting, creases in paper, or additional notes from the editors. In moving from archival boxes to screens, the complexity, diversity, and physicality of the archive is inevitably reduced, but is a necessary form of translation as would be any form of engagement with the archive.

\section{Translation 2: From Film to Digital Interface}

The last and ongoing translation from film to digital interface is one that also requires a digital intermediary, this time a database in MySQL so that the clips can be pulled into the interface via a query system. While the digital interface is incomplete and undergoing varying experiments, the intermediary is expected to remain the same. We mention it here as another significant step towards this next translation to reveal additional types of labour that are not visible in what is considered the "final product."

This translation is where the co-authors started a collaborative effort to think about what a digital interface might offer. On the one hand, Lusztig had filmed 306 readings and only 28 made the cut 
to the film, so there was an opportunity to include additional letters in a digital interface. And on the other hand, we were both wary to "dump" it all in online, label it as an archive, and allow readings to be experienced as discrete individual viewing experiences, for three main reasons: (1) in order to recognise the collective aspect of the archive, we knew an intentional curatorial and authorial framework was needed, (2) we wanted to pay attention to the design choices we made with the interface and to consider how those choices would affect the viewing of these readings, and (3) we also wanted to pay attention to the kinds of decisions tied to the coding that affect an interface but are traditionally ignored. ${ }^{2}$

Rather than adopt a querying system as a point of entry into the archive, we are working to develop methods that might allow the possibility of random encounters within the archive. In the digital interface, a starting point we are working to emulate is the act of opening the boxes, folders, and tabs of the analogue materials, in order to make space for discovering, learning, and encountering letters a visitor is not necessarily expecting to find. In addition, we are considering options for an intersectional querying method that would align with the idea above. After the presentation of the box of folders, the user is presented with themes from which they can select a display of videos in an additive manner on a second page. We decided to work with a hexagonal grid of videos that would reveal ties between various letter readings based on theme, in dialogue with the conceptual ideas about the intersectional feminist conversations that structure the project. 


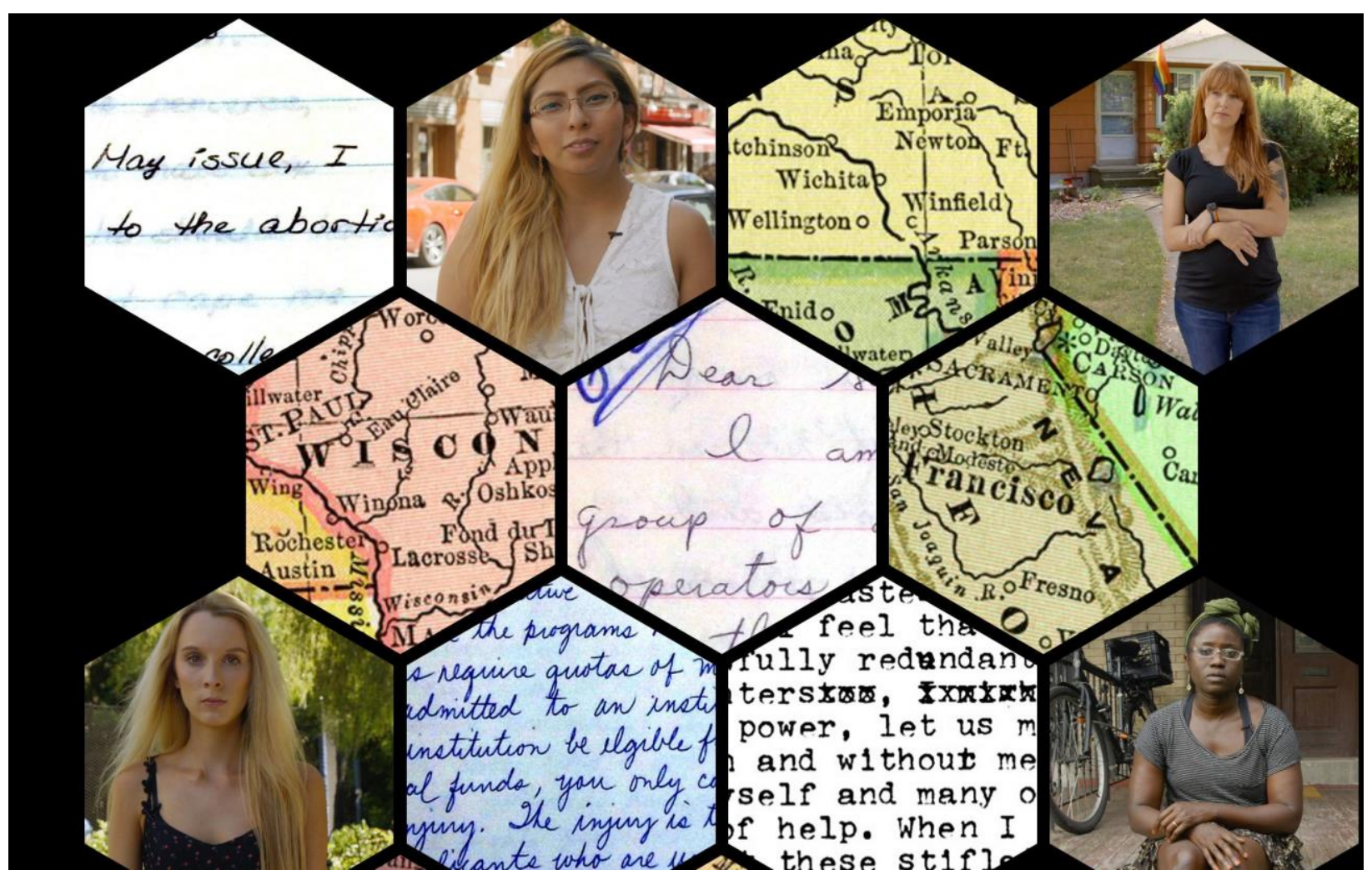

Figure 5. Screenshot interface of work-in-progress web page showing hexagonal grid

After the initial display, videos reorganise and reshape the grid based on the themes as well as the location of the letter readers. This grid would be different for each viewer in two ways: (1) it is first generated based on the viewer's selection of themes, resulting in a grid of overlapping selected themes, and (2) as the viewer selects particular videos to view, the grid transforms based on their journey of viewing. We used a simple query system based on the database from the film, modified to include filenames and paths, and simplified to include themes and location. The reshaping of the grid is the most interesting device, as it results in a different viewing based on the selections of the user. In this sense, it builds on the concepts of polyphonic and fragmented narratives in the field of interactive documentary. For instance, idocs scholars Judith Aston and Stefano Odorico lean on Mikhail Bakthin's concept of polyphony and its relation to dialogue to analyse idocs that not only are collaborative in their mode of participation but also in their aesthetics. ${ }^{3}$ In this case, 
Frames Cinema Journal, Issue 19 (March 2022)

in addition to the multiplicity of voices emerging from the letters which contribute to a polyphony in content, the multiple different versions of viewings also contribute to a polyphonic form.

On the one hand, this translation from film to digital interface results in a few losses. For example, the digital interface does not afford the linearity and controlled pace that the film does. In addition, the amount of time the filmmaker can expect a film viewer to engage with the online iteration of the project is significantly shorter. ${ }^{4}$ On the other hand, this translation also offers some gains. An obvious gain is the scale of the project in terms of the number of readings. This translation to a web space allows for an additional gain: the move from an individual/singular talking-head to a collectively linked one. It was important to us to place everyone in a collective space to see multiple people at once who make this project, an opportunity afforded to us by the browser's canvas which provides a different framework than the sequential edit of the film. While the intermediary database between the boxes of letters to film included a map with 800 pins, location is only rendered visible in the film through burnt-in captions in the landscape transitions before each reader. In the digital interface, as a user makes their way through the readings, additional hexagons show up, thus revealing a connection to location that creates links between letter writer and subsequent reader.

\section{Conclusion}

Thanks to the work of scholars including Michelle Caswell, Marika Cifor, and Lae'l HughesWatkins among others, the field of archival studies has seen a recent shift in understanding and advocating for countering the negative effects of archival work on communities who have been categorised and misrepresented in order to further colonial, settler, and/or other kinds of oppressive violence. The legacies of that archival work find their way into many of the contemporary practices 
in academic and cultural institutions including the practices of evaluation, ordering, classification, organisation, and description. To that end, this article uses a feminist and decolonial framework to examine workflows entailed in moving an archive from one medium to another, with deliberate attention to the labour, the decision-making, and the losses and gains of these moves. Studying this work as a kind of translation allows for reflection on the decisions made by the authors involved at each stage. For critical translation studies scholars Kadiu and Robinson, the act of translation is understood as a continuously reflexive decision-making process. For example, when Lusztig decided to use the teleprompter for shooting the readings she repurposed the tool that was traditionally used for newsrooms and political debates for the purposes of creating discourse around sisterhood.

The decisions about what letters to include in the database, when and how they are displayed, what kind of grid to use, how to link readings, and why not to use a map, not only consist of design choices but are manifestations of translations of documents and their enclosures. Analysing each of these steps as translations allows for an assessment of the labour involved at each stage. For example, Lusztig carefully read through the entire archive of letters, made choices, developed a system for choosing letters, and created a database to find common themes, which then served as a way to cast individuals to read the letters. None of this labour figures in the film, and from the fields of cinema studies, our language and frameworks limit this work to research or preproduction work. However, if we conceptualise this process as a translation of an interface to an archive, from folders to a film, then we can take into account the various kinds of interpretation made throughout. 
Frames Cinema Journal, Issue 19 (March 2022)

\section{Notes}

${ }^{1}$ Letters to Ms., 1972-1980: A Finding Aid, Arthur and Elizabeth Schlesinger Library on the History of Women in America, Radcliffe Institute for Advanced Study, Harvard University, October 1981.

${ }^{2}$ Here, we hint at "database dump," the term used to describe a record for the database, often in sql, used for backing up the database.

${ }^{3}$ See Aston, J. and Odorico, S. "The poetics and politics of polyphony: towards a research method for interactive documentary" Alphaville: Journal of Film and Screen Media, 15 (2018): 63-93.

https://doi.org/10.33178/alpha.15.05.

${ }^{4}$ We do not have the data yet for how long people spend on the website but we expect it to be much less based on web viewership of similar idocs.

\section{Bibliography}

Caswell, Michelle and Marika Cifor. "From Human Rights to Feminist Ethics: Radical Empathy in Archives" Archivaria 81 (Spring 2016): 23-43.

Caswell, Michelle, Marika Cifor, and Mario H. Ramirez. "“To Suddenly Discover Yourself Existing': Uncovering the Impact of Community Archives." The American Archivist 79, no. 1 (June 2016): 56-81.

Cox, Richard J. No Innocent Deposits: Forming Archives By Rethinking Appraisal. Lanham, MD: Scarecrow Press, 2004.

D. Andy Rice“"The Sense of Feminism Then and Now: Yours in Sisterhood (2018) and Embodied Listening in the Cinema Praxis of Irene Lusztig" Senses of Cinema, 2018.

Kadiu, Silvia. Reflexive Translation Studies: Translation as Critical Reflection. 1st edition. London: UCL Press, 2020.

Lae'l Hughes-Watkins, “Moving Toward a Reparative Archive: A Roadmap for a Holistic Approach to Disrupting Homogenous Histories in Academic Repositories and Creating Inclusive Spaces for Marginalized Voices," Journal of Contemporary Archival Studies 5 (2018): https://elischolar.library.yale.edu/jcas/vol5/iss1/6/ 
Frames Cinema Journal, Issue 19 (March 2022)

Letters to Ms., 1972-1980; unpublished letter to Ms., 1974. MC 331. Schlesinger Library, Radcliffe Institute, Harvard University, Cambridge, MA.

Lubow, Arthur. "Hands Off the Library's Picture Collection!" The New York Times, August 3, 2021, sec. Arts. https://www.nytimes.com/2021/08/03/arts/design/new-york-public-librarypicture-collection.html.

Lusztig, Irene. "Listening Across Difference: Feminist Conversation, Sisterhood, and the '70s." Senses of Cinema. May 2021, Issue 98. https://www.sensesofcinema.com/2021/featurearticles/listening-across-difference-feminist-conversation-sisterhood-and-the-70s-2/

Moodie, Megan. "Handmade Feminism: Irene Lusztig's Yours in Sisterhood," Los Angeles Review of Books, 11 May 2018, https://lareviewofbooks.org/article/handmade-feminismirene-lusztigs-yours-in-sisterhood/

Robinson, Douglas. Critical Translation Studies. 1st edition. London and New York, NY: Routledge, 2017.

Thylstrup, Nanna Bonde. The Politics of Mass Digitization. Cambridge, MA: The MIT Press, 2019.

Thylstrup, Nanna Bonde, Daniela Agostinho, Annie Ring, Catherine D’Ignazio, and Kristin Veel, eds. Uncertain Archives: Critical Keywords for Big Data. Cambridge, MA: The MIT Press, 2021. 


\section{Author Biographies}

Fabiola Hanna is an Arab-American artist/scholar. Her practice and research merge at the intersection of memory work, digital archives, and software studies. She is currently working on both a multimedia narrative intelligence project on the contested history of Lebanon and a book on historical justice in digital environments. Fabiola holds a PhD in Film and Digital Media from UC Santa Cruz, where she completed an MFA in Digital Arts \& New Media. She is Assistant Professor of Emerging Media at the School of Media Studies at The New School.

Irene Lusztig is a feminist filmmaker, visual artist, and archival researcher. Often beginning with rigorous research in archives, her work brings historical materials into conversation with the present day, inviting viewers to contemplate questions of politics, ideology, and the production of personal, collective, and national memories. She is the solo director, producer, DP, and editor of three acclaimed feature length documentaries that have screened widely in festivals and are distributed by Women Make Movies: her debut film Reconstruction (2001), the feature length archival film essay The Motherhood Archives (2013), and the performative documentary Yours in Sisterhood (2018). She teaches filmmaking at the University of California, Santa Cruz, where she is professor of film and digital media. 